\title{
The Virtues of Nonsimulation Games
}

\author{
LAYMAN E. ALLEN - University of Michigan \\ ROBERT W. ALLEN - Nova University
}

JOAN ROSS - University of Michigan

\begin{abstract}
Non-simulation games are
accompanied by statistically

significant increases in scores

on standard I. Q. tests.
\end{abstract}

The use of games as teaching devices is receiving attention from an increasing number of educators. ${ }^{1}$ Data from tests conducted with one such educational game-WFF 'N PROOFstrongly indicate that this and similar games are useful, not only in teaching a particular subject (in this case symbolic logic), but also in increasing the general problem-solving ability of the student.

WFF 'N PROOF is actually not one game but a series of 21 games of increasing difficulty. The first games in the series are quite simple and can be enjoyed by first graders. The final games are challenging and stimulating even for a university teacher of logic.

The first two games of WFF 'N PROOF are designed to teach the concept of WFF (or well-formed formula). This concept is usually thoroughly learned before proceeding to the proof games. The WFF games place a premium on speed, and young children clearly enjoy them.

The proof games are much more difficult, and the most advanced of them are comparable to chess in complexity. 
Before playing a proof game, two new concepts are needed: that of rule of inference and that of proof. These may be learned either from an experienced player or from the programmed material in the playing manual which comes with the game. The manual also has some suggestions for rule-practice games which may precede the proof games. An interesting proof game may be played with three rules of inference. The ultimate proof game and last game in the series uses eleven assumed rules of inference. These rules of inference are introduced one at a time in the manual, and there is a learning program for each. A rule-practice and proof game can be played at each level (i.e., using any or all of the rules of inference introduced up to that point).

The game rules themselves (as distinct from the rules of inference which are part of the subject matter of the game) are designed so that each player must give the game his constant and full attention. To win the game, he must solve a series of problems which are set for him by his fellow players. He, in turn, sets problems which the other players must try to solve. Thus a premium is placed on creating and solving problems which are at the outer limits of the player's knowledge of the subject matter. If the players are evenly matched, each player will be able to solve most of the problems posed for him and thus he will get the immediate reinforcement of success. Since he views the problems as difficult, his self-confidence will be enhanced. This supplies motivation to attempt the mastery of further ideas (especially since chances of winning may be increased by such learning). The teacher may introduce a new idea by a discreet intrusion into the play of a game and then leave it to the winners to disseminate the idea in the course of winning games by using that new idea. In general, the teacher's role is shifted toward more individualized instruction than is the case in the usual classroom situation. He serves primarily as adjudicator of the inevitable differences that arise between two or three players. Thus, instead of expounding subject matter to a large passive audience, he is supplying much-wanted infor- 
mation to a small group of actively interested participants. Of course, WFF ' $N$ PROOF also has the usual game advantages of excitement at something new, association with recreation, and participation in a pleasant social situation.

Through the use of WFF 'N PROOF, a teacher can create a highly indulgent classroom situation. Naturally, care must be taken to see that each player is playing with other players on his level. One is not likely to learn much or achieve very positive attitudes toward the subject matter if he is always losing. One easy way to arrange that wits are matched instead of overwhelmed is to have a hierarchy of game tables with pupils matched initially according to teachers' previous knowledge of performance in several tryout games, and then to bump losers down one table and winners up one table after each session of play. ${ }^{2}$

A natural extension of the kind of playing session described above is the inter- or intrascholastic tournament. Teams from various classes or schools or even school systems may meet to compete in intellectual competition. This idea was suggested by James Coleman (1961: 320-322) as a way of introducing into the American high school a reward for mental talent that is comparable to the usual reward for physical talent (via athletic competition). ${ }^{3}$

WFF ' $N$ PROOF was tested in the kind of setting described above when forty-three junior high and high school students studied and played WFF 'N PROOF in a summer-school course on logic at a suburban California high school. The class met for three weeks, five days a week, four hours a day. Only WFF' $N$ PROOF materials were used. The students advanced in the games at their own pace but had to request and pass a test before they could progress to the game at the next level. The decision as to who would play whom was made by the students. They could challenge anyone at their level (or above) to a game. Grades were awarded on the basis of how far they had advanced and on test scores. Some students advanced to the level of the twenty-first game. The California Test of Mental Maturity 1957 
S-Form, Junior High School and Advanced was administered as a pretest on July 2, 1964, and as a posttest on July 21, 1964. This test was used because it was the one already being used in the guidance program at the school.

The control group consisted of those enrolled in the course in pre-algebra conducted at the same school that summer. Thus, both the experimental and control groups were self-selected by the courses that they voluntarily enrolled in. The control group was taught by a different teacher. The same tests were administered to the control group on July 6, 1964, and July 29, 1964.

Figure 1 is a plot of the frequency distributions of the changes in scores for the two groups. It is obvious that the big changes came in the nonlanguage part of the test of the experimental group. Table 1 summarizes the data and shows this very plainly. For example, the mean change in score of all the experimental students on the nonlanguage test was over twenty points while the control group gained less than seven points on the average. There seems to be some small effect of improvement at the repetition of the test, but the improvement of the experimental group's nonlanguage test scores is much too big to be explained by such an effect.

A t-test was used to test the significance of the differences in the means of the nonlanguage score changes, and they were all found significant at the .01 level. The degrees of freedom for the $\mathrm{t}$-distribution were adjusted downward to compensate for the differing variances.

A similar experiment was conducted in a previous year (Allen et al., 1966: 22-25) with similar results except that in that year the boys accounted for almost all the gains and the girls' scores did not change significantly. In the present experiment, the boys' and girls' changes were not significantly different. Boys and girls are listed separately to show this lack of difference.

These results, showing a mean increase in nonlanguage I.Q. score of more than twenty points, are in sharp contrast with the results reported in the articles reviewed by Cleo H. Cherry- 


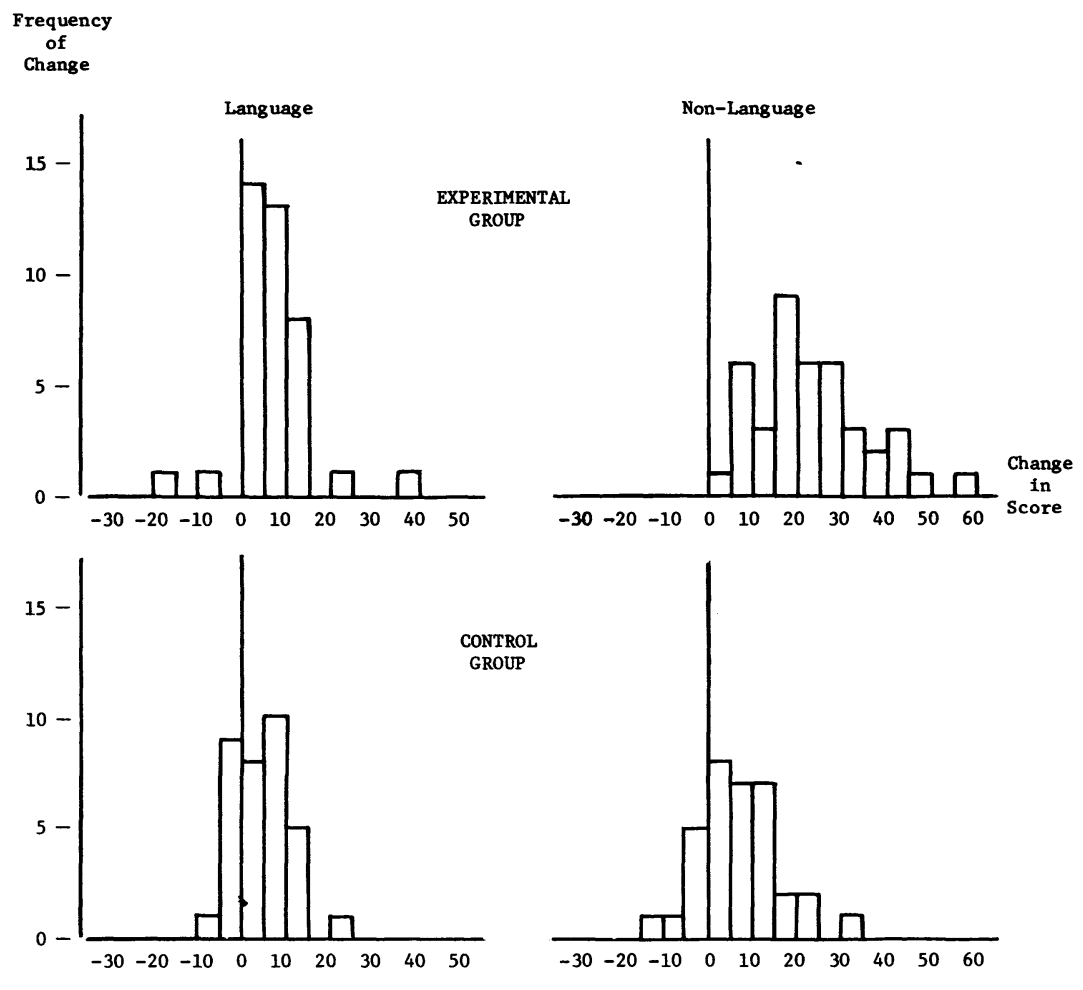

Figure 1. DISTRIBUTION OF CHANGES IN SCORES

holmes (1966), ${ }^{4}$ but there is a likely explanation of the discrepancy. All the games considered in the Cherryholmes paper are simulation games, such as the John Hopkins Life Career game and a simulation of international relations of Science Research Associates. These games are designed to give the student a vicarious experience of the working of some system or process. The purpose of such a game is to influence one who has played it to behave more rationally or effectively when he comes in contact with the same or a similar system outside the classroom. The date cited by Cherryholmes indi- 
TABLE 1

SUMMARY OF DATA

COMPARISONS OF MEAN SCORES AND CHANGES IN SCORES

\begin{tabular}{|c|c|c|c|c|c|}
\hline \multirow[b]{2}{*}{ Group } & \multirow{2}{*}{$\begin{array}{l}\text { Number } \\
\text { in Group }\end{array}$} & \multicolumn{2}{|c|}{ Mean Score } & \multirow{2}{*}{$\begin{array}{c}\text { Mean } \\
\text { Change }\end{array}$} & \multirow{2}{*}{$\begin{array}{l}\text { Standard Error } \\
\text { of Mean Change }\end{array}$} \\
\hline & & Pretest & Posttest & & \\
\hline \multicolumn{6}{|l|}{ LANGUAGE } \\
\hline All-Experimental & 43 & 116.9 & 122.8 & 5.9 & 1.2 \\
\hline All-Control & 34 & 110.2 & 114.4 & 4.2 & 1.1 \\
\hline Boys-Experimental & 28 & 118.2 & 123.6 & 5.4 & 1.3 \\
\hline Boys-Control & 23 & 111.2 & 115.8 & 4.6 & 1.4 \\
\hline Girls-Experimental & 15 & 114.5 & 121.1 & 6.7 & 2.6 \\
\hline Girls-Control & 11 & 108.2 & 115.5 & 3.4 & 1.4 \\
\hline \multicolumn{6}{|l|}{ NON-LANGUAGE } \\
\hline All-Experimental & 43 & 107.6 & 128.4 & 20.9 & 2.1 \\
\hline All-Control & 34 & 108.2 & 114.8 & 6.6 & 1.6 \\
\hline Boys-Experimental & 28 & 108.8 & 131.2 & 22.4 & 2.6 \\
\hline Boys-Control & 23 & 110.4 & 117.7 & 7.3 & 2.1 \\
\hline Girls-Experimental & 11 & 105.3 & 123.3 & 18.0 & 3.3 \\
\hline Girls-Control & 11 & 103.6 & 108.7 & 5.1 & 2.5 \\
\hline
\end{tabular}

cates that, while student interest may be stimulated by such games, there is no evidence that they stimulate learning or problem-solving. If we are concerned with the efficacy and efficiency of games as pedagogical devices, it is clear from this article that, so far, the case for simulation games is "not proven." It is to be hoped that this conclusion will in no way discourage experimentation with and further development of these games. It seems clear that they have tremendous potential.

However, since many teachers who may be considering using games in their classrooms may have read the Cherryholmes review, we feel it important to emphasize that data show that WFF 'N PROOF and similar games ${ }^{5}$ must be exempted from the conclusions of that article. This is hardly surprising since WFF ' $N$ PROFF is not a simulation game-in fact it is an entirely different kind of game from any considered there. The main 
difference is that the goal of WFF 'N PROOF is to (a) teach its content, symbolic logic, while developing more favorable attitudes toward such symbol-handling activities as those encountered in the game, and (b) teach problem-solving by stimulating the solution of real (not simulated) problems. All the data point toward justified optimism about the efficacy of nonsimulation games in general and WFF 'N PROOF-type games in particular. We would go further and claim that this kind of game is likely to be an excellent tool for (a) teaching the content of any formal system and (b) teaching the fine art of problem-solving in general.

These nonsimulation games are particularly appropriate for the implementation of the Coleman idea of intellectual competition to parallel the athletic competition in schools. It is a general characteristic of simulation games that almost all the information to be extracted from them is garnered after playing several times. The WFF 'N PROOF games are essentially open-ended and can thus be profitably played repeatedly. ${ }^{6} \mathrm{~A}$ further advantage is that the outcome of these nonsimulation games is less dependent on manipulation of people than on manipulation of symbols; thus their use in serious competition tends to lead to fewer refereeing problems than the use of simulation games.

Although nonsimulation games differ from the simulation variety in respects other than those by which woman differs from man, it behooves us all to be aware of the profoundness of the differences-and perhaps also vive.

\section{NOTES}

1. Two recent general discussions are given in Scholastic Teacher Report (1967), which also includes a very useful list of pedagogical games, and Carlson (1967).

2. Teams are of use in giving a player the chance to identify with a group to which he contributes his scores and ideas and whose members may in turn contribute to his learning. In fact, considerable intrateam learning usually occurs. 
A good way to stimulate interest and excitement is to publish a newsletter to report the results of each playing session. This newsletter should include cumulative scores-both team and individual-and as many players' names as possible. It should be in the hands of the participants as soon as is possible after the session it reports. It may also contain problems-perhaps those encountered in actual play and reported by the students.

3. See also the article by Carlson (1967) which describes National Academic Games Olympics.

4. American Behavioral Scientist (1966) contains a good bibliography on stimulation games as learning devices. An important omission for this list is the work of Brian Sutton-Smith, Professor of Psychology at Bowling Green State University, Bowling Green, Ohio. Of particular interest is Sutton-Smith (1955: 261-263; 1964).

5. There are three games in the WFF ' $N$ PROOF series: WFF 'N PROOF, ON-SETS (about set theory), and EQUATIONS (about elementary arithmetic). The game rules of the three are very similar; the main difference is in the content.

6. In particular, a recently developed extension of EQUATIONS (called Adventurous EQUATIONS) makes possible the use in the game of a substantial number of the ideas of the high school and college freshman mathematics curriculum. This is done by requiring the players to introduce their own rules! For a description of Adventurous EQUATIONS, see the WFF'N PROOF Newsletter, (1968).

\section{REFERENCES}

AlleN, L. E., R. W. ALlEN, and J. C. MILlER (1966) "Programmed games and the learning of problem-solving skills: the WFF 'N PROOF example." J. of Educational Research 60 (September): 22-25.

American Behavioral Scientist (1966) 19 (October).

CARLSON, E. (1967) "Games in the classroom." Saturday Rev. of Literature (April 15).

CHERRYHOLMES, C. H. (1966) "Some current research on effectiveness of educational simulations: implications for alternative strategies." Amer. Behavioral Scientist 19 (October).

COLEMAN, J. S. (1961) The Adolescent Society. New York: Free Press. Scholastic Teacher Report (1967) "Games in the classroom." Reprint of articles from Scholastic Teacher (November 9).

SUTTON-SMITH, B. (1964) "What play tells you about children." Education 4 (May). WFF 'N PROOF Newsletter (1968) Winter.

---(1955) "The psychology of children's games." National Education (New Zealand) 37: 228-229 ff. 